\section{MIGRATION OF LEPIDOPTERA}

T ARGE-SCALE movements of butterflies have long attracted attention, as when in A.D. 1100 it was recorded, appropriately enough in a "History of Calamities", that swarms of butterflies were seen passing from Saxony to Bavaria. In 1508 "an innumerable swarme of whit butterflyes coming so thick as flakes of snow" was noted at Calais. It is clear that dense flocks, such as were cormmon in the towns along the south coast of England in 1939-40, are not the result of modern conditions. The keen interest of Dr. C. B. Williams has led to much close study of the subject, on which an isuportant paper has recently been published*. Dr. Williams claims that these movernents are not a mere exodus from an area of food scarcity to a land of plenty, but a reaI migration in the sense that they are comparable with the familiar to and fro seasonal movements of birds. Evidence to this effect is particularly striking in the case of Danaus plexippus, the Milkweed butterfly or Monarch. This well-known species, of North, Central, and South America, occurs in different races with different, though overlapping, geographical distribution. The northern and southern races undertake large migrations, the central one does not. The northern race, p. plexippus, appears to have spread over a large part of the globe, and is the one which is occasionally captured in England. Its movements have been closely studied in the south-eastern United States, and it is clear that there is a definite northward movement in the spring, the last butterflies leaving Florida when the mean temperature rises above $75^{\circ} \mathrm{F}$., and arriving in the north (reaching well into Canada) after the mean exceeds $50^{\circ} \mathrm{F}$. There is definite evidence of their absence from Florida in the summer : they begin to return with corresponding temperatures.

Along the Pacific coast their behaviour has for some time been notorious, for their over-wintering sites are well known in California. The places chosen are dense groups of trees, preferably evergreens; almost every suitable locality is favoured, and the butterflies congregate at the same spot year after year in dense masses; these places are the termini of the return southward migration. The vexed question of whether the specimens taken in England have flown across the Atlantic or have travelled on ships cannot yet be decided. There is a record of several specimens caught by an officer of a ship outward bound from Glasgow; they were playing round the rigging about two or three hundred miles from British shores. But no records of large flights seen on the open sea, such as have been made for Pieridæ and the familiar Painted Lady, are to hand for plexippus, nor have they been recorded by light. house-keepers like some other migrants. Evidence of return migration for some other species is accumulating and is particularly clear in the case of Dione vanilla: good evidence is increasing for nine other species, including the Silver Y moth, Plusia gamma. Dr. Williams discusses the evolutionary difficulty of understanding how the instinct to migrate is perpetuated if outward movements occur regularly without return flight. It is probable that the more closely the question is studied the more evidence will come to hand of return flight, and Dr. Williarns says, "I can still point to no butterfly in which the absence

* Studies in the Migration of Lepidoptera. By Dr, C. B. Williams, Soc. Lond., 82, 101-283. of a return flight has been established beyond reasonable doubt".

The direction of these migratory flights is not primarily connected with the direction of the wind, for diagrams in which every recorded flight is plotted as an arrow head along points of the compass show little correlation with prevailing wind. It is concluded that the orientation of individuals flying in a cross-wind shows that they do appreciate, and allow for, wind direction, but there is no evidence that the wind determines the direction of any migratory flight. Nor can the direction be associated with the position of the sun: "When one has seen a migration continue steadily in one almost compass-true direction for several weeks on end, at all times of the day and in all weathers except perhaps heavy rain, it is difficult to believe that the direction of the sun's rays can have any importance." Very remarkable is an observation from Lake Ontario: a flight of $D$. plexippus was seen by an observer, fishing in Port Bay, a narrow southward arm of the lake. The butterflies were going south but at a short distance south of the observer they made a sharp left turn, crossed the bay, a distance of about a quarter of a mile, then made a right turn and headed south again.

Experiments to ascertain whether migrants appreciate, or orientate themselves in relation to, a magnetic field produced no evidence. It is not necessary, to establish the occurrence of a migration, that the butterflies should pass in noticeable swarms; the important point is the steady passage of numbers in one direction. Evidence of a migration was produced by observing about twenty butterflies passing in twenty minutes over a front of about one hundred yards. Such a movement, however, needs expert watching and repeated observation. It is thus quite possible that more evidence of return migration can be obtained. At the other end of the scale are snowstorm migrations in which the insects are too numerous to be counted even on a short front. In one flight of the African skipper Andronymus neander, it was estimated that five hundred per minute were crossing on a front of twenty-two yards. Attempts have been made to treat butterflies like migrating birds by marking and releasing many at a time. So far it has not been done on a scale large enough to give results, for extremely few recoveries have been made at any distance. Statistically, however, much can be learnt from the rate of disappearance of the marked individuals from the place where they were marked. Interesting evidence that migratory movements are due to widespread factors is provided by a statistical study of correlation between the movements in America and Europe of the well-known Striped Hawk moth (Celerio lineata) and the Painted Lady (Vanessa cardui). It appears that there is a tendency for large migrations to occur simultaneously in both continents. Similarly, within the British Isles there is some correlation between movements of different species of immigrants : thus Plusia gamma is usually abundant when Vanessa cardui is.

The destruction of migratory butterflies on a large scale by birds has often been recorded, and the dismembered wings of Pieris brassicae were frequently noted in many parts of England during 1940.

The Insect Immigration Committee of the South Eastern Union of Scientific Societies is responsible for the collection of evidence of movements, and more help is much needed. Only by the continued detailed study of large masses of data can many vexed questions be decided. G. D. HaLe Carpenter. 